\title{
Comparative study on health care system between Myanmar and China according to World health organization (WHO)'s basic health blocks
}

\author{
May Kyi Lwin ${ }^{1}$, Mingjiang $\mathrm{Xu}^{2}$, Xinhua Zhang, ${ }^{1}$ * \\ ${ }^{1}$ Department of Social Medicine and Health Service Management, School of Information and Management, Guangxi Medical University, \\ Nanning, PR China \\ ${ }^{2}$ Faculty Humanity and Social Science, Guangxi University of Chinese Medicine, Nanning, PR China \\ Email address: \\ mychan21@gmail.com (M. K. Lwin), xumingjiang@gxtcmu.edu (Mingjiang Xu), zhangxinhuayikeda@163.com (Xinhua Zhang)
}

\section{To cite this article:}

May Kyi Lwin, Mingjiang Xu, Xinhua Zhang. Comparative Study on Health Care System between Myanmar and China According to World Health Organization (WHO)'s Basic Health Blocks. Science Journal of Public Health. Vol. 3, No. 1, 2015, pp. 44-49.

doi: $10.11648 /$ j.sjph.20150301.18

\begin{abstract}
To compare the health system between Myanmar and China's health system as the following ways- WHO describes these functions in terms of six components or building blocks: 1.services delivery, 2.health workforce, 3.health information, 4.access to essential medicines 5.health financing, 6.leadership or government. Data were collected publicly set of World Health Organization (WHO), World Bank, statistically year books, publicly available reports, documents and published medical literatures. Descriptive and comparative approaches were used. Myanmar health system is mixed with public and private system. Not like Myanmar, China mainly depends on public system. Hospital beds of Myanmar are lower than China and could not cover the total population. Both countries have mal distribution of health workforce because of hard to reach areas, rural and remote areas, low incentive and deficiency of basic facilities. The scope and quality of health information of Myanmar has some limitations and for China is improve quickly with new technologies. Accessing of essential medicines availability and affordability need to be improved in both countries. Myanmar government could not put investment as much as China. The government of both countries should have more effort to get their goals of health system. Both of health system should learn from each other and from other countries to perform the better health success.
\end{abstract}

Keywords: Comparative Analysis between China and Myanmar, WHO's Six Basic Health Blocks, Health System, Health Status

\section{Introduction}

\subsection{General Health Status between China and Myanmar}

Health system stem from specific political, historical, cultural, and socio-economic tradition and the difference in these tradition result in the difference in organization arrangement of health care. Without health care, human life qualities will be declined. China as a developing and Myanmar as under developing country, have similarities and differences in health system. Myanmar is the largest country among ASIAN countries and it opened in past and open in last few years and now it embarked on a path of political and economic reforms in 2011, paving the way for developing the country's large potential. China opened its door to the world from 1978, after over 30 years reform China has become more powerful in both economic and political sides and pay more attention to healthcare. The health status between China and Myanmar shows in table 1.

Table 1. General health status of Myanmar and China

\begin{tabular}{lcc}
\hline & Myanmar & China \\
\hline Total population(000s) & 52,797 & $1,384,77$ \\
Total expenditure on health & & 0 \\
as \% of GDP & 1.8 & 5.1 \\
Life expectancy at birth(year) & 66 & 75 \\
Gross national income per capita (PPP int.\$) & $1950^{*}$ & $7640^{*}$ \\
$2012 *$ & 92 & 94 \\
Literacy rate(\% age 15 and above) & 92 \\
\hline
\end{tabular}




\begin{tabular}{lcc}
\hline & Myanmar & China \\
\hline Population living in urban areas (\%) & 33 & 51 \\
Annual population growth rate (\%) & 0.7 & 0.6 \\
Neonatal mortality rate(both sex) & 32 & 11 \\
Population using improved drinking water (\%) & 92 & 86 \\
Prevalence of smoking any tobacco product & Male 47 & Male 38 \\
among adult aged $\geq(\%)$ & Female 2 & Female 7 \\
\hline
\end{tabular}

Source: World health statistics 2014, * world health statistics 2012

Total expenditure on health of China increases 4.6 to 5.1 from 2000 to 2011. But in Myanmar, growth decrease 2.1 to 1.8 from 2000 to 2011. Life expectancy at birth of China is 67 to 74(years) in male and 71 to 77(years) in female and in Myanmar, 57 to 64(years) in male and 61 to 68 in female from 1990 to 2012 relatively. Neonatal mortality is decrease from 25 to 9 in China but in Myanmar decrease 41 to 26 within 22 years that is nearly one-third much more than China. Literacy, especially female, has a major impact on health status and utilization of health care. Hence, lower literacy rate may act an additional factor behind the lower coverage rate of immunization and antenatal care along the high rate of child mortality and maternal mortality [1-2]. On the other hand, Myanmar and China have the literacy rate of more than $90 \%$ and have higher coverage of antenatal care and immunization [3].

To access the effective services are still faced with some problem of the health system. China accepted their health care system has inequalities, inadequate prevention and shortage of human resources [4]. Myanmar is low income country and China is upper income country [3]. Poverty is one of the main challenges to improve the health status and health system in Myanmar and have the multiple health problems with limited resources [5]. China is experiencing a disease spectrum shift as a rapid epidemiological transition. In addition to this, deaths due to non-communicable diseases (NCDs) are more than due to communicable diseases such as heart diseases, hypertension and diabetes [6]. At the same time, Myanmar is facing double burden of communicable and non-communicable diseases (NCDs) which sometimes transform to chronic type and mostly causes by tobacco use, unhealthy diet, harmful use of alcohol and some other causes [7].

\section{Method}

The main data sources for this paper were from World Health Organization of World health statistical books, World Health Reports, WHO-China Country Cooperation strategy, WHO-Myanmar Country Cooperation Strategy and Documents from Ministry of Health of Myanmar. For the international literature review, we used data and paper collection by search engines and Guangxi Medical University library and its online library. The collected literatures are from 2006 to 2014, especially from 2011 to 2014 literatures are used. The data and papers mainly focus on health delivery, health workforce, health information, essential medicine, health financing and government performance on health system of both countries.

\section{Result}

We designed the paper basic on six main parts of health system to describe and compare the performance, process and functioning on health system of China and Myanmar.

\subsection{Service Delivery}

The Ministry of Health (MOH) of Myanmar has seven departments and made responsible for the preventive, pro motive, curative and rehabilitative health services. Health services are provided by the township hospital, station hospital, urban and rural health centers and sub-rural health centers [8]. About 450 to 800 major natural disasters in each year are occurred around the world. Myanmar also has the impact of these natural disasters and sometimes has impact of the outbreak. While they are occurred, people have the effect of diseases, injury, infectious and deaths, etc. At these times need rapid response to effected areas but for bordering China townships have low coverage, poor infrastructure and poor access of health care because some areas are hard to reach, hard to communicate (language) and cultural difference [9-10].

Health services in China are mainly provided by the public system. Health system is organized by four levels of national, provincial, city and county. Under theses four administrative levels include have different institutions which perform different responsibilities [11]. Community health centers served as on prevention, medical care, health care, recurring services, health education and family planning. Community health delivery system is speeded up after 2008 and in 2009 the Chinese government started to carry out the community health delivery system reform and also join to promote the patient's life satisfaction [12-13].

When says to health service delivery, "hospital, hospital beds and psychiatric beds" are essential parts of it. Without these basic infrastructure can not complete the health system services. Both Myanmar and China have private and public hospital system for the population. Hospital bed of Myanmar is six-fold lower than China and number of hospital of Myanmar also need to improve to cover the population.

Table 2. Hospital, hospital beds and psychiatric beds in China and Myanmar

\begin{tabular}{cccc}
\hline & \multirow{2}{*}{ Hospital } & \multicolumn{2}{c}{ per10 000population } \\
\cline { 3 - 4 } & & Hospital beds & Psychiatric beds \\
\hline China & $9166^{\mathrm{a}}$ & $38^{\mathrm{c}}$ & $1.4^{\mathrm{c}}$ \\
Myanmar & $924^{\mathrm{b}}$ & $6^{\mathrm{c}}$ & $\ldots$ \\
\hline
\end{tabular}

Data receives from ${ }^{\mathrm{a}}$ Health services delivery profile China ${ }^{\mathrm{b}}$ WHO-Myanmar country cooperation strategy $2014-2018^{\mathrm{c}}$ World health statistics 2014

\subsection{Health Workforce}

The world today is still facing many challenges including some new challenges to achieve our common goals of 
universal coverage of health service and health for all. The urbanization in many newly developed countries as China and in some developing countries as Myanmar, migration of population from rural areas to urban areas as well as from urban to urban is increasing rapidly which cause increasing burden to health service system and demand on more health workforce at urban areas. At the same time, migration of skilled health workers from rural to urban causes the further loss of health workers at rural areas or small cities. The loss of health human resources represents a loss in the capacity of health systems to deliver health care equitably [13-14]. Health workforce is the most important resources for successful implementation of National Health Vision and Mission [15]. Middle and low income countries such as China and Myanmar also faced with health workforce shortage and inequality in distribution of health personnel [16].

Table 3. Density of health workforce in China and Myanmar

\begin{tabular}{lcc}
\hline Health workforce(10 000 population) & China & Myanmar \\
\hline Physicians & 14.6 & 6.1 \\
Nursing and midwifery personnel & 15.1 & 10 \\
Dentistry personnel & $\ldots$ & 0.7 \\
Pharmaceutical personnel & 2.6 & $\ldots$ \\
Psychiatrics & 0.1 & $<0.05$ \\
\hline
\end{tabular}

Data sources come from World health statistics 2014

The ratio of the physicians to nurses and midwives in China and Myanmar was 1.0 and 0.5 respectively, whereas China has two fold resulting than Myanmar. The health resources are seriously lack, the basic facilities are very simple and inadequate and the medical personnel are shorted [4]. China is different from other countries because the data shows 1.9 million licensed doctors and 1.4 million nurses in 2005 [13]. Myanmar is one of the 57 countries faced with human resource shortage and mal-distribution, only has 1.3 workers (doctors, nurses, midwives) per 1000 population [14]. Inequality distribution of the ratio of midwifery skilled provider to village is $1: 2$ [9].

\section{Panel 1. Description of health professionals of Myanmar}

Health professionals include doctors, dentists, pharmacists, nurses, traditional medical practitioners, technical staff, midwives, village health workers.

Doctors- are those pass 7 years of long education. In addition to it one year if house surgeon training. Licensed doctors are medical graduates from medical universities. After graduated, taking two weeks of cultivation program and have an exam for licenses.

Dentists-need 6 years to study. Entrance is according to Matriculation examination.

Nurses- after matriculation exam, according to nursing university required scores can apply the university. For licenses, no examination is required. Pharmacists- according to required scores can apply the university. No examination is required for license.

Traditional medical practitioners- studied at traditional medical university. Technicians- include laboratory technician, radiology technician, physiotherapy technician.
Panel 2. Description of health professionals of China

Health professional include doctors, nurses, pharmacists, laboratory technicians, clinical radiologists and other technical staff with advanced education.

Doctors- are those who pass a licensing examination and registered at a country or higher level health authority as either licensed doctors or licensed assistant doctors.

Nurse- who have obtained nursing certification with an associated degree (3 years' tertiary nursing education or higher or graduates from secondary education programmes with a diploma (2 years' nursing education after high school) and recommended by a health authority at provincial level or above. No examination is required.

Technicians- are professionals who have undertaken specialized studies and include pharmacist, laboratory technicians, radiology technicians and other graduates

Data sources from Ministry of China and Ministry of Myanmar

\subsection{Health Information}

Health information system (HIS) in Myanmar started in 1987 and hospital records, public health service records and administration records are used as a main source of HIS. Core group Myanmar health information strategic plan was established in 2009 [17]. Improving data quality, data collection, data compilation and data quality assessment play an important role of HIS. Hence, the health system can get the accuracy data for better performance implementation [18]

After SARS outbreak, China health information system (HIS) put effort for the better process. Routine Health Statistics Information System (RHSIS) function for the main HIS system which takes responsible for collecting data. Furthermore, national centers for disease control and prevention (CDC), department of maternal and child health, department of health inspection and supervision and department of planning and financing also take the responsible for the data collection of their relative functions. China ministry of health puts more investment to provide HIS development for health system [19].

\subsection{Access to Essential Medicine}

Myanmar essential Medicines project was started in 1988 and national drug law is promoted in 1992. The food and drug administration department monitor the quality and affordable essential medicines [20]. Approximately $80 \%$ of essential medicines products are from domestic origin. Traditional medicines flourish significantly by a major part of Myanmar culture and produce by private and public producers [21]. For primary health care facilities in China make the procedure according to National Essential Medicines List and province based procurement system [22]. The China government does tasks for appropriate reforms for the essential medicines form production to distribution systems [4]. Since 2011, China government use governmentrun primary healthcare facilities with zero-markup drug sales [8]. Traditional Chinese Medicine (TCM) is a unite part for the China health system services and also exported to 163 Countries around the world [23]. Median availability of selected medicines (\%) of China is 15.5 by public and 13.3 by private but for Myanmar, no data are described [3]. 


\subsection{Health Financing}

Myanmar government health investment is uncovered to total population and health fair is poor. Poor population can't afford to go to hospital for their healthy problems. Although the government put more investment as three-fold between 2001 and 2006, the health is still under resource. One of the main reasons for Myanmar common people is health insurance. Most of the hospital charges are out of pocket. In this condition, the poor people have financial problem to go to hospital. In 2003, the general government expenditure on health is $19.4 \%$ of all expenditures the left-over $80.6 \%$ was out of pocket [7, 8, 24]. According to 2012 World health statistics the data are described as table.

Table 4. Health expenditures of China and Myanmar

\begin{tabular}{lcc}
\hline & China & Myanmar \\
\hline $\begin{array}{l}\text { Total expenditure on health as \% of GDP } \\
\text { Private expenditure on health as \% of total } \\
\text { expenditure on health }\end{array}$ & 5.1 & 2.1 \\
$\begin{array}{l}\text { General government expenditure on health } \\
\text { as \% of total expenditure on health }\end{array}$ & 52.5 & 11.3 \\
$\begin{array}{l}\text { Out of pocket expenditure as \% of private } \\
\text { expenditure on health }\end{array}$ & 78.9 & 92.4 \\
\hline
\end{tabular}

Data received from 2014 World Health Statistics

The China's government makes the policy to increase the economic condition and to decrease the poverty, but the health system has no improving as well as the economy after 1978. By 2001, private health expenditure was $61 \%$ and decrease to $44 \%$. The government started the 3 years (20092012) investment plan as 1.13 trillion RMB [25]. Sales of medicines and services became the main source of operational funds for public facilities [26]. In 2011, the China government supports main investment for health insurance coverage by the basic social medical insurance system and now health insurance coverage up to $90 \%$ by 2013 [27]. Health insurance is effective for the maternal and child mortality in rural China. Insurance system of most countries supports for the better health insurance to increase the social and health welfare and also does China [28].

\subsection{Government}

Like China government, Myanmar government makes the policy to improve the health sector. National Health Policy expressed "health for all" and equality of basic health services in 1993. Ministry of health (MOH) in Myanmar had drawn the National Health Plan 2011-2016 to meet the Myanmar health vision 2030 [8]. Under the guidance of China government, China's National Development and Reform Committee declared the China health reform in 2008. The government put the large investment for health prevention, health education, health insurance, pharmaceutical industry as well as related health functions. The China health reform has monitored by the local government China ministry of health but still remains challenges [29-30].

Millennium developed goals (MDGs) are established as 8 goals for United Nations countries in 2000. MDGs are high priority for both China and Myanmar especially health related MDG 4, 5 and 6 . Under 5 mortality rate and infant mortality rate of Myanmar is higher than China. For instance, Myanmar maternal mortality ratio declined from 580 to 200 within 1990 to 2013, but still higher than China. The declined rate of global maternal ratio is $1.4 \%$ between 1990 and 2000 and between 200 and 2013 the rate increases to 3.5\% [1]. HIV/AIDS data of China for MGD 6 are limit and Myanmar data are described as follows.

Table 5. Trends in health related MGD indicators in China and Myanmar

\begin{tabular}{|c|c|c|c|}
\hline Health related indicator & & China & Myanmar \\
\hline \multirow[t]{2}{*}{ MDG 4} & $\begin{array}{l}\text { Under } 5 \text { mortality rate(probability of } \\
\text { dying by age } 1 \text { per } 1000 \text { live births) }\end{array}$ & 14 & 52 \\
\hline & $\begin{array}{l}\text { Infant mortality rate (probability of } \\
\text { dying by age } 5 \text { per } 1000 \text { live births) }\end{array}$ & 12 & 41 \\
\hline MDG 5 & $\begin{array}{l}\text { Maternal mortality ratio } \\
\text { (per } 100000 \text { live births) } \\
\text { Prevalence }\end{array}$ & 32 & 200 \\
\hline \multirow[t]{5}{*}{ MDG 6} & HIV(per 100 000population) & $\ldots$ & 371 \\
\hline & Tuberculosis (per 100 000population) & 99 & 489 \\
\hline & $\begin{array}{l}\text { Causes specific mortality rate } \\
\text { per } 100000 \text { population }\end{array}$ & & \\
\hline & HIV/AIDS & $\ldots$ & 22 \\
\hline & Tuberculosis among HIV negative people & 3.2 & 48 \\
\hline
\end{tabular}

Source: World Health Report 2014

\section{Discussion}

In this paper, we present the health system of Myanmar and China. Moreover, current situation of human resource to provide the systemic framework for entire system are also described.
We analyze the health status of the population which is regarded as overall goal of our health system. In Myanmar, the number of hospitals per 10,000 populations is lower than the China. Myanmar government should invest to build hospitals in rural and hard to reach areas. The density of hospital beds shows inpatient service. Traditional medicine of 
China and Myanmar are improving nowadays. The measure of health system performance should concentrate on health delivery which can improve the health of population.

Following the urbanization, migration of population from rural areas to urban areas as well as from urban to urban is increasing rapidly which cause increasing burden of health service system and demand on more health workforce at urban areas of both countries. Imbalances in the workforce are the major concern and human resource management is essential element in many countries and also in China and Myanmar. Globally, nurses and midwives personnel represent the higher number and density of health workforce than the physician and other health workers.

In contract, the number and the density physicians are higher than the number and the density of nurses and midwives in China. There are about 1.9 million physicians in China (2000-2009), which was about six hundred higher than the total number of nurses and midwives personnel. Unlike China, Myanmar has higher number and the density of nurses and midwives than the physicians resulting to the higher nurse to physician ratio than China. At the same time, one of the main problems is very difficult to see doctor and treatment is very expensive Following the urbanization in many newly developed countries and in some developing countries, migration of population from rural areas to urban areas as well as urban to urban is increasing rapidly which cause increasing burden to health service system and demand on more health workforce at urban areas.

For the whole system, government investment plays in main role and also health infrastructure. Actually, Myanmar's health system suffers from weak health information system for performing the health system. Then in China health information system can establish the administrative and organization framework and shows the improvement in the health statistical work. On the other hand, it can't access the HIS development in west areas of the China where have poor infrastructure.

For curing diseases, essential medicine plays in important role. Access of generic medicine of China shows increasing availability but for Myanmar lower than the China. Although many processing are made for China's health system, access to affordable health services, quality and access of essential medicines remain as a problem. If traditional medicine is safety and efficacy, it will support some part of medicine for population of China and Myanmar. If the government can perform insurance, people have more healthy life than before. For the people in rural and remote areas, people who are low educated still use invalid drugs. Although the government employs a lot of medical workers, there is still luck in rural and remote areas. In China, the government invests total expenditures on health insurance to develop the population health status. The reform of large investment also covers for grass root health institution and health training for all health services. For insurance, the local government support and accomplish to collect and allocate funds and operate the scheme, which is different between city or province.

Myanmar doesn't have health insurance system not like as other neighboring countries. As in China, according to health reform health insurance system is developed and out of pocket charges are decreased. According financing in South East Asia region survey 2009, level of out of pocket health expending of South East Asia region is over 60\%. As for China of private health expenditure is nearly $48 \%$ and for Myanmar is over $80 \%$. Myanmar health system mixed of public and private system both in the financing and provision parts. Sometimes it is organized and provided by public and private providers. Today some private organizations play in critical role in providing aids around Myanmar. China's health reform was started in 2009 for 3 years plan, which is the first step to achieving goals in 2020. On the economic side, annual rate is also increased $9.7 \%$ from 1978 to 2006. The rapid economic growth of China over last decade gives the fundamental changes and lifting more than million people from poverty.

In Myanmar, there are a lot of necessaries for implementing objectives and goals. Recent years Non Government organizations (NGOs) are also increasing significantly. In rural and remote areas still need health education and health services and also faced with Medical workforce shortage. Medical professions want to work in capital city and some large cities. Medical workforce is also important in social security system. Now health system is improving by government investment and private contribution and constitution of NGOs and International Non Government Organization (INGOs). Fulfilling the strategies and objective of health related millennium development goals (MDGs), there should have government support and private supports. Therefore, people will have a perfect health system and healthy lives.

\section{Conclusion}

To meet the challenges faced by countries and achieve necessary changes and significant investments are needed. In addition to increase investments to strengthen institutions that provides the education and social health status of the nations. Allocated resources should be used to build and to strengthen the capacity of the ministries of the health to manage the health system to hit the health goal of both Countries.

\section{References}

[1] Verena I Carrara, Celia Hogan: Improved pregnancy outcomes in refugees and migrants despite low literacy on the ThaiBurmese border: results of three cross-sectional surveys; BMC Pregnancy Childbirth. 2011 Jun 17;11:45. doi: 10.1186/14712393-11-45.

[2] Improving maternal newborn and child health in Myanmar. Available at: http://searo.who.int/LinkFiles/

[3] WHO World Health Statistics 2014: Geneva; World health organization www.who.int, http://apps.who.int/iris/bitstream/10665/112738/1/9789240692 671_eng.pdf?ua=1 
[4] WHO-China country cooperation strategy 2008-2013. Available at: http://wenku.baidu.com/link?url=1k2SIbfn4wlm6n0Ksr6ej77e jeE6DulD0jxdzCl51IUrM2KXQC3iaMGhLVrSTjzS5x8Aci0ujlFZglPwkmppedxSf2IRsiYi6lmToHXyi

[5] WHO-Myanmar country cooperation strategy 2013-2015 Available at: http://www.who.int/countryfocus/cooperation_strategy/ccs_m mr_en.pdf

[6] WHO-China country cooperation strategy 2013-2015, World health organization

[7] WHO-Myanmar country cooperation strategy 2014-2018, World health organization http://www.searo.who.int/myanmar/CCS_Myanmar.pdf

[8] Myanmar health care system 2013; Ministry of health of Myanmar http://www.moh.gov.mm/file/MYANMAR\%20HEALTH\%20 CARE\%20SYSTEM.pdf?DED48128=6AC29DE4

[9] Nilar Tin, Saw Lwin, Nyo Nyo Kyaing; An approach to health system strengthening in the Union of Myanmar; Elsevier Health Policy. 2010 May;95(2-3):95-102. doi: 10.1016/j.healthpol.2009.11.013. Epub 2009 Dec 16.

[10] Nyan Win Myint,Jaranit Kaewkungual, Pratap Singhasvanon; Are there any changes in burden and management of communicable diseases in areas affected by Cyclone Nagis? Bio Med Central; Conflict and Health 2011, 5:9 doi:10.1186/1752-1505-5-9

[11] Health service delivery profile (China 2012): Developed in collaboration with WHO and China National Health development research center. Available at: http://www.wpro.who.int/health_services/service_delivery_pr ofile_china.pdf

[12] Liyang Tang; The Chinese community patient's life satisfaction, assessment of community medical service and trust in community health delivery system; Bio Med Central Health and Quality of Life Outcomes 01/2013; 11(1):18. DOI: 10.1186/1477-7525-11-18

[13] Sudhir Anand, Victoria Y Fan, Junhua Zhang: Health system reform in China 5: China's human resources for health: quantity, quality and distribution; www.lancet.com Vol 372:1774-1781, November 15, 2008

[14] Managing Health Workforce 2013; Ministry of health of Myanmar 2013 http://www.moh.gov.mm/file/MANAGING\%20HEALTH\%20 WORK\%20FORCE.pdf?DED48128=6AC29DE4

[15] Uta Lehmann, Marjolein Dieleman: Staffing remote rural areas in middle and low-income countries: A literature review of attraction and retention; BMC Health Serv Res. 2008 Jan 23;8:19. doi: 10.1186/1472-6963-8-19.

[16] Islam M: Progress towards achieving Millennium development Goals 5 in South-east Asia: BJOG201, 118(Supp12):6-12
[17] Health information system (Five year strategic plan 20112015), Ministry of Health

[18] Evidence for decision (Ministry of Health Myanmar) Available at: http://www.moh.gov.mm/file/EVIDENCE\%20FOR\%20DECI SION.pdf

[19] China health information system: Review and assessment 12,2006 , By center for health statistics information, Ministry of health (China)

[20] Access to essential medicine, Ministry of Health (Myanmar) http://www.searo.who.int/myanmar/documents/HealthinMyan mar_2012_8c_AEM.pdf

[21] Traditional medicine2013. Ministry of Health Myanmar http://www.moh.gov.mm/file/TRADITIONAL\%20MEDICIN E.pdf?DED48128=6AC29DE4

[22] Winnie Chi-Man Yip, William C Hsiao: Early appraisal of China's huge and complex health care reforms. www.lancet.com Vol379 833-842, March 3, 2012

[23] Judy Xu, Yue Yang ; Traditional Chinese medicine in the Chinese health system; Elsevier Health Policy 90(2009) 133139 dio: 10.1016/j.healthpol.2008.09.003

[24] Yu Mon Saw, Khine Lae Win, Laura Wen-Shuan Shiao; Taking stock of Myanmar's progress toward the health-related Millennium Development Goals: Current roadblocks, paths ahead; Int J Equity Health. 2013 Sep 11;12:78. doi: 10.1186/1475-9276-12-78.

[25] Hu S, Tang S, Liu Y: Trends in access to health services and financial protection in China between 2003 and 2011: a crosssectional study; Lancet. 2012 Mar 3;379(9818):805-14. doi: 10.1016/S0140-6736(12)60278-5.

[26] Yan-China Weaves world largest net of medical care Xinhua English news (Beijing), May30, 2011

[27] Cheng Li, Xuan Yu, James R.G Butler; Moving towards universal health insurance in China: Performance, issues and lessons from Thailand; Elsevier Social Science\& Medicine Volume 73, Issue 3, August 2011, Pages 359-366 doi:10.1016/j.socscimed.2011.06.002

[28] Yuyu Chen, Ginger Zhe: Does health insurance coverage lead to better health and educational outcome? Evidence from rural China; J Health Econ. 2012 Jan;31(1):1-14. doi: 10.1016/j.jhealeco.2011.11.001. Epub 2011 Dec 9.

[29] The Twelfth Five-year plan for health sector development in China http://www.britishchamber.cn/content/chinas-twelfthfive-year-plan-2011-2015-full-english-version

[30] Healthcare in China: Infrastructure, Government\& healthcare 2009 KPMG, a Hong Kong partnership and a member firm of the KPMG network of independent member firms affiliated with KPMG international, a Swiss cooperation. Available at: http://wenku.baidu.com/view/820bdf9b51e79b896802267a.ht $\mathrm{ml}$ ?re=view 